\title{
WHITE MATTER DEMENTIA
}

Cerebral white matter disorders affecting behavior and cognition are reviewed from the University of Colorado School of Medicine, and Denver VA Medical Center. Diffuse white matter pathology disrupts attentional systems, frontal lobe function, visuospatial skills, and emotional status, while sparing language abilities. White matter behavioral disorders have a greater capacity for recovery than gray matter disorders, possibly related to remyelination. However, a pure white matter disorder is uncommon, and gray matter is frequently implicated. The prototype white matter disease, multiple sclerosis, is frequently complicated by cognitive and emotional dysfunction. Other white matter disorders asociated with dementia include metachromatic leukoencephalopathy, tolueneabuse leukoencephalopathy, AIDS dementia complex, traumatic brain injury, and hydrocephalus. Most white matter disorders are diffuse but some are focal, resulting in aphasia, alexia, agraphia, apraxia, agnosia, or akinetic mutism. The MRI and diffusion-weighted MRI may identify new examples of white matter involvement in behavioral disorders. (Filley CM. The behavioral neurology of cerebral white matter. Neurology June 1998;50:1535-1540). (Reprints: Dr Christopher M Filley, Behavioral Neurology Section, UCHSC B-183, 4200 East Ninth Ave, Denver, CO 80262).

COMMENT. The neurobehavioral disorder characteristic of white matter dementia is defined by deficits in sustained attention, memory retrieval, visuospatial skills, frontal lobe function, and emotional status, with preserved language and extrapyramidal function. Deficits in right frontal lobe function are explained by the relatively greater amounts of white matter in the right compared to left hemispheres.

\section{CARBON MONOXIDE COGNITIVE IMPAIRMENT}

Neuropsychological tests were administered to 45 students exposed for 2 hours to carbon monoxide in low concentrations (mean, $61 \mathrm{ppm}$ ) from residential kerosene stoves and results compared to 47 nonexposed control students at the Hebrew, Haddasah, and Ben-Gurion Universities, Jerusalem, Israel. Venous blood carboxyhemoglobin levels ranged from 0.01 to 0.11 . CO exposed students scored significantly lower on tests of memory, new learning ability, attention and concentration, tracking skills, visuomotor skills, abstract thinking, and visuospatial planning and processing. (Amitai Y, Zlotogorski Z, Golan-Katzav V, Wexler A, Gross D. Neuropsychological impairment from acute low-level exposure to carbon monoxide. Arch Neurol June 1998;55:845-848). (Reprints: Yona Amitai MD, Department of Pediatrics, Hadassah University Hospital Mt Scopus, Jerusalem 91240, Israel).

COMMENT. Low-level carbon monoxide exposure results in impairments of higher cognitive function similar to those previously reported in patients with moderate $\mathrm{CO}$ poisoning. Early symptoms of $\mathrm{CO}$ poisoning consist of headache and fatigue, followed by dizziness and syncope. Subtle signs of CO exposure may require psychological tests for their detection.

\section{VALIDITY OF DSM-IV ADHD CRITERIA IN YOUNGER CHILDREN}

The validity of DSM-IV criteria for each subtype of ADHD was evaluated in 126 children, aged 4 through 6 years, and 126 matched controls at the University of Chicago. Children who met DSM-IV diagnostic criteria according to parent interviews and teacher reports differed from controls on a wide range of measures of social and academic impairment. Criteria for all three DSM subtypes were valid for identification of children with ADHD, aged $4-6$ years. (Lahey BB, 
Pelham WE, Stein MA et al. Validity of DSM-IV attention-deficit/hyperactivity disorder for younger children. I Am Acad Child Adolesc Psychiatry July 1998;37:695-702). (Reprints: Dr Lahey, Department of Psychiatry (MC 3077), University of Chicago, 5841 South Maryland Ave, Chicago, IL 60637).

COMMENT. DSM-IV criteria for subtypes of ADHD are valid in younger children, aged 4 through 6 years. All children diagnosed with ADHD showed significant functional impairments in behavior, attention, and social skills, and deficits in academic achievement.

\section{NEUROBEHAVIORAL OUTCOME IN CRANIOPHARYNGIOMA}

The records of 20 children with craniopharyngioma seen between 1983 and 1995 were reviewed at the University of Colorado Health Sciences Center, Children's Hospital, and the Denver VA Medical Center, CO. Post-surgical social behavior and school performance were assessed by neuropsychological tests and standardized rating scales over a mean follow-up period of 38 months. Moderate or severe impairment of neurobehavior occurred in $12(60 \%)$, and only 3 had a good outcome. The outcome was independent of partial or gross total resection of the tumor. The possible adverse effects of radiation therapy used in $17(85 \%)$ could not be evaluated, but the age at the time of irradiation and the degree of dysfunction were not related. The common feature of the tumors was location in diencephalic and adjacent limbic regions, and the direct involvement of these structures appeared to correlate with neurobehavioral impairments. (Anderson CA, Wilkening GN, Filley CM, Reardon MS, Kleinschmidt-DeMasters BK. Neurobehavioral outcome in pediatric craniopharyngioma. Pediatr Neurosurg May 1997;26:255-260). (Respond: C Alan Anderson MD, Department of Neurology, University of Colorado Health Sciences Ctr, Denver, CO).

COMMENT. Behavioral assessments in addition to psychological testing are important in the pre- and post-surgical and -irradiation treatment of craniopharyngioma. The cognitive effects of cranial irradiation in children with acute lymphoblastic leukemia are reviewed in Progress in Pediatric Neurology III, PNB Publishers, 1997;pp424-6).

\section{DEGENERATIVE DISEASES}

\section{JUVENILE FAMILIAL AMYOTROPHIC LATERAL SCLEROSIS}

Four cases of JFALS in a family, with mean age at onset of 15.7 years and exceptionally long survival (mean, 27 years), are reported from the National Institute of Neurology and Neurosurgery, Mexico City. The father developed the classic form of ALS at 63 and died 2 years later. Three of the children had severe, and one moderate, dementia in adulthood. Cognitive deterioration began a few years after onset. MRI in one patient showed severe atrophy of cortex and brain stem, but the classic pyramidal degeneration was slight. (Siliceo EO, ArriadaMendicoa N, Balderrama J. Juvenile familial amyotrophic lateral sclerosis: four cases with long survival. Dev Med Child Neurol June 1998;40:425-428). (Respond: EO Siliceo MD, Torcuato Tasso 335-401, Chapultepec Morales 11570, Mexico DF, Mexico).

COMMENT. A juvenile form of familial ALS has an onset in late childhood and a long survival, complicated by dementia. Genetic analysis in FALS show 20\% linked to chromosome 21q21, and the remaining $80 \%$ unidentified (Siddique T et al. Neurology 1996;47 (Suppl 2):27-35). 